\title{
Low fingertip temperature rebound measured by digital thermal monitoring strongly correlates with the presence and extent of coronary artery disease diagnosed by 64-slice multi-detector computed tomography
}

\author{
Naser Ahmadi • Vahid Nabavi · Vivek Nuguri · Fereshteh Hajsadeghi · \\ Ferdinand Flores · Mohammad Akhtar · Stanley Kleis · Harvey Hecht • \\ Morteza Naghavi · Matthew Budoff
}

Received: 16 January 2009/ Accepted: 7 July 2009/Published online: 26 July 2009

(C) The Author(s) 2009. This article is published with open access at Springerlink.com

\begin{abstract}
Previous studies showed strong correlations between low fingertip temperature rebound measured by digital thermal monitoring (DTM) during a 5 min arm-cuff induced reactive hyperemia and both the Framingham Risk Score (FRS), and coronary artery calcification (CAC) in asymptomatic populations. This study evaluates the correlation between DTM and coronary artery disease (CAD) measured by $\mathrm{CT}$ angiography (CTA) in symptomatic patients. It also investigates the correlation between CTA and a new index of neurovascular reactivity measured by DTM. 129 patients, age $63 \pm 9$ years, 68\% male, underwent DTM, CAC and CTA. Adjusted DTM indices in the occluded arm were
\end{abstract}

N. Ahmadi · V. Nabavi · V. Nuguri · F. Hajsadeghi ·

F. Flores $\cdot$ M. Budoff $(\bowtie)$

Los Angeles Biomedical Research Institute, Harbor

UCLA Medical Center, 1124W. Carson Street, RB2,

Torrance, CA 90502, USA

e-mail: mbudoff@labiomed.org

M. Naghavi

American Heart Technologies, Houston, TX, USA

H. Hecht

Lenox Hill Heart \& Vascular Institute, New York, NY, USA

M. Akhtar · S. Kleis

University of Houston, Houston, TX, USA calculated: temperature rebound: aTR and area under the temperature curve aTMP-AUC. DTM neurovascular reactivity (NVR) index was measured based on increased fingertip temperature in the nonoccluded arm. Obstructive CAD was defined as $\geq 50 \%$ luminal stenosis, and normal as no stenosis and $\mathrm{CAC}=0$. Baseline fingertip temperature was not different across the groups. However, all DTM indices of vascular and neurovascular reactivity significantly decreased from normal to non-obstructive to obstructive CAD [(aTR $1.77 \pm 1.18$ to $1.24 \pm 1.14$ to $0.94 \pm 0.92)(P=0.009)$, (aTMPAUC: $355.6 \pm 242.4$ to $277.4 \pm 182.4$ to $184.4 \pm$ 171.2) $(P=0.001)$, (NVR: $161.5 \pm 147.4$ to $77.6 \pm$ 88.2 to $48.8 \pm 63.8)(P=0.015)]$. After adjusting for risk factors, the odds ratio for obstructive CAD compared to normal in the lowest versus two upper tertiles of FRS, aTR, aTMP-AUC, and NVR were $2.41(1.02-5.93), P=0.05,8.67$ (2.6-9.4), $P=0.001,11.62(5.1-28.7), P=0.001$, and 3.58 (1.09-11.69), $P=0.01$, respectively. DTM indices and FRS combined resulted in a ROC curve area of 0.88 for the prediction of obstructive CAD. In patients suspected of CAD, low fingertip temperature rebound measured by DTM significantly predicted CTA-diagnosed obstructive disease.

Keywords Digital thermal monitoring . Framingham risk score - Computed tomography angiography $\cdot$ Coronary artery disease 


\section{Introduction}

Despite major advances in the treatment of coronary artery disease (CAD), a large number of apparently healthy people die suddenly of a heart attack without prior symptoms and do not benefit from existing preventive therapies. Therefore, early detection and treatment of at risk individuals for primary prevention of CAD is of grave importance. Traditional cardiovascular assessment methods such as the Framingham Risk Score (FRS), which rely solely on risk factor measurement, are useful for long term prediction of risk at population levels, but are grossly inaccurate and insufficient for individualized assessment of risk [1-3]. Measurement of risk factors such as high cholesterol does not show the vascular health of an individual. Therefore, noninvasive, individualized, direct assessment of vascular health that is superior to the FRS is needed. Multiple noninvasive imaging modalities (ultrasound, computed tomography, magnetic resonance imaging) can aid in cardiovascular risk assessment but are not feasible (due to high cost and potential adverse effects) for screening healthy populations and need for repeated uses in primary prevention settings. A low-cost and easy-to-perform test capable of direct measurement of vascular function that would provide additive value to FRS is, therefore, needed. Such a test may also complement vascular structural imaging tests such as coronary artery calcium (CAC) score and carotid intima-media thickness [4-6].

Vascular dysfunction is generally considered a key initial event in the atherosclerotic process which is a systemic disorder local manifestation. Numerous studies have shown that functional changes in arteries precede the development of structural changes and also reverse more quickly in response to therapies [7, 8]. Fingertip Digital Thermal Monitoring (DTM) of vascular reactivity is a new non-invasive, operator-independent test based on changes in fingertip temperature during and after arm cuff occlusion. DTM has been shown to correlate with the burden of subclinical coronary atherosclerosis in asymptomatic patients, measured by coronary artery calcium and nuclear perfusion imaging [9-12]. The present study was designed to evaluate whether vascular dysfunction measured by DTM correlates with the presence and extent of
CAD diagnosed by computed tomography angiography (CTA) in patients with suspected coronary artery disease (CAD).

\section{Methods}

Subjects and study design

The study population includes 129 consecutive patients with suspected CAD who were referred to the CTA laboratory: 68 with typical angina, 39 with atypical angina, 15 with equivocal exercise stress tests, and seven with shortness of breath. All subjects underwent coronary artery calcium (CAC) scanning, CTA and DTM. Subjects over 35 years were eligible to participate. Patients with established cardiovascular disease, stroke, diabetic retinopathy, end-stage renal disease, Raynaud's syndrome, infection, cancer, immunosuppression, systemic inflammation, and end-stage renal or liver disease were excluded. Body mass index, waist circumference, blood pressure, fasting blood glucose, and lipid profile were obtained by standard techniques. Risk factors were determined and Framingham risk score (FRS) calculated [13].

\section{Study protocols}

\section{Digital thermal monitoring of vascular reactivity}

All DTM measurements were performed in the morning in a quiet, dimmed room at a controlled ambient temperature between 23.5 and $25.0^{\circ} \mathrm{C}$. Female participants were examined during the follicular phase of their menstrual cycle. Studies were conducted after an overnight fast of at least $10 \mathrm{~h}$ (water was permitted) and abstinence from tobacco, alcohol, caffeine, vasoactive medications, exercise, high-fat foods and vitamin $\mathrm{C}$. The measurements were obtained with the subjects supine and after 30 min of rest. Each patient's blood pressure in the control arm was recorded in a sitting position $5 \mathrm{~min}$ before the DTM test (IntelliSense ${ }^{\circledR}$ Professional Digital Blood Pressure Monitor, HEM-907XL, Omron Inc, Illinois). DTM of both hands was obtained during $5 \mathrm{~min}$ stabilization, $5 \mathrm{~min}$ cuff inflation to $50 \mathrm{mmHg}$ greater than systolic blood pressure, and 5 min deflation using an automated, operator-independent protocol (VENDYS, Endothelix Inc., 
Houston, TX). Thermal changes during a 5 min armcuff induced reactive hyperemia test were monitored continuously in the fingertip of both the occluded and non-occluded arms using VENDYS software. The device consists of a computer based thermometry system $\left(0.006^{\circ} \mathrm{C}\right.$ thermal resolution) with two fingertip RTD (Resistance Temperature Detector) fast response probes designed to minimize the skin-probe contact area and fingertip pressure, attached to the pulp of the index finger on both hands. The system includes a common automated sphygmomanometer cuff, cuff-inflation pump, and release valve to permit noninvasive measurement of arterial pressure and the control of occlusive hyperemia. Dual channel temperature data are simultaneously acquired at a $1 \mathrm{~Hz}$ sampling rate.

\section{DTM indices}

Figure 1a shows DTM indices of vascular reactivity measured based on the amount of temperature rebound (TR) and area under the temperature curve (TMP-AUC) in the fingertip of the occluded arm.
Neurovascular reactivity (NVR), thermal changes in non-occluded arm during and after reactive hyperemia, was similar in the arm and finger cuff occlusive reactive hyperemia procedure $(r=0.96$, $P=0.0001)$. Infrared Imaging shows the changes in new DTM index of neurovascular reactivity (NVR) measured based on the area under the fingertip temperature curve in the non-occluded arm during reactive hyperemia procedure. The fingertip temperature changes in the occluded arm are shown in red line and the blue line shows temperature changes in the non-occluded arm. Figure 1b illustrated a good vascular reactivity, TR and TMP-AUC, (Top) and good neurovascular reactivity, NVR (Bottom).

\section{Adjustment of DTM indices}

aTR and aTMP-AUC were computed to account for variations in both test site conditions, such as ambient temperature and air velocity [14], and variable patient features, such as finger size, finger thermal physical properties and temperature drop from inlet arteries to venous return [15-19]. A lumped capacity energy

\section{a}

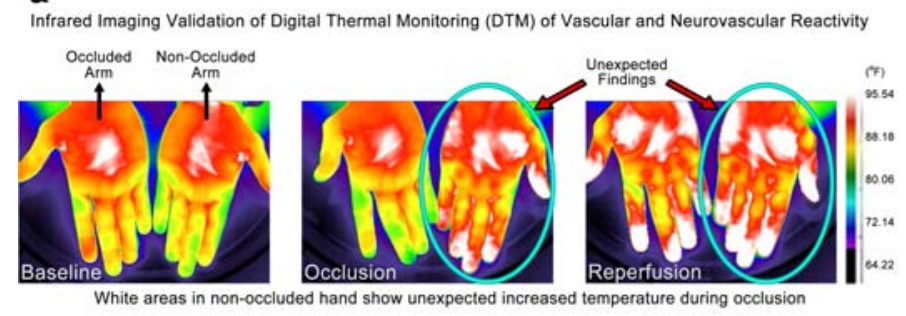

Digital Thermal Monitoring (DTM) of Vascular Reactivity and Neurovascular Reactivity

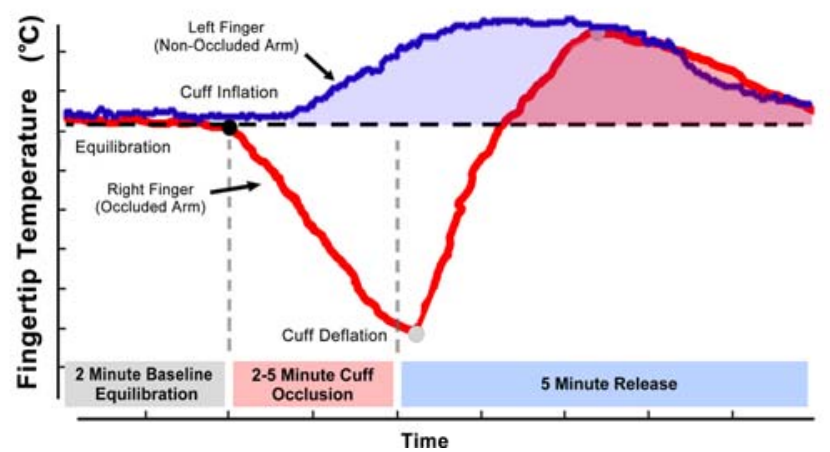

b

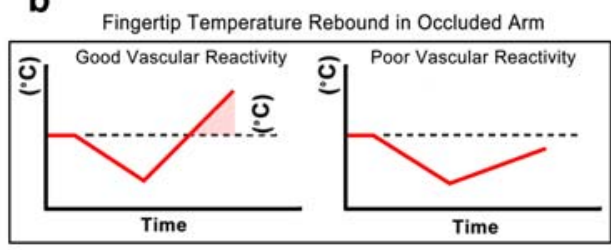

Changes in Fingertip Temperature in Non-Occluded Arm

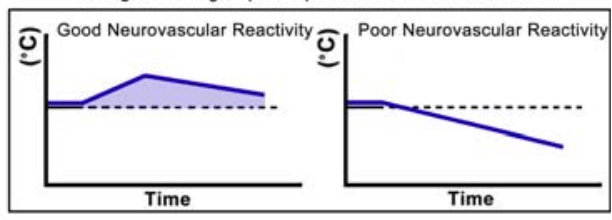

Fig. 1 Skin temperature changes during cuff-reactive hyperemia, as shown by infrared imaging and digital thermal monitoring $(D T M)$. Infrared imaging reconfirms increase in non-occluded arm fingertip temperature during reactive hyperemia procedure. Both arm and finger cuff reactive hyperemia had similar neurovascular reactivity $(r=0.96, P=0.0001)$ 
balance for a finger in a room with air movement shows that the finger temperature under steady state conditions depends upon the size and orientation of the finger, the ambient temperature and air flow conditions, and the finger blood flow rate and temperature drop from inlet arteries to venous return. In addition, the fall of finger surface temperature during complete occlusion of the arteries supplying blood flow depends upon the size and thermal physical properties of the finger.

From measurements of the steady state finger surface temperature and the transient response of surface temperature to occlusion, the finger thermal time constant and the heat loss characteristics to the surrounding room can be determined. This information can be used to predict the finger temperature recovery after release of occlusion for the case of zero vascular reactivity in response to the occlusion. That is, the solution to the temperature recovery assuming a step change in blood perfusion rate back to the original steady state value before occlusion can be computed. By using this solution as a baseline for comparison, the temperature increase above the zero reactivity case can be computed and used as an indication of the amount of reactive hyperemia present after release of occlusion.

One of the advantages of this approach is that the ambient temperature and ambient air flow conditions are accounted for in the zero reactivity predictions and, thus, their effects on the final results are reduced. Also, the resulting signal has a well defined maximum and area under the curve, since the difference signal starts and ends at zero temperature difference. aTR and aTMP-AUC provide indicators of the amount of reactive hyperemia present during the recovery from occlusion.

\section{Coronary artery calcium scanning}

The studies were performed with an E-Speed electron beam scanner (EBCT) (GE-Imatron, South San Francisco, CA, USA). The coronary arteries were imaged with 30-40 contiguous $3 \mathrm{~mm}$ slices during enddiastole using ECG-triggering during a $35 \mathrm{~s}$ breath hold. CAC was considered present in a coronary artery when a density of $>130$ Hounsfield units (HU) was detected in $\geq 3$ contiguous pixels $\left(>1 \mathrm{~mm}^{2}\right.$ ) overlying that coronary artery; it was quantified using the previously described Agatston scoring method [20].

\section{Computed tomography angiography}

Beta blockers were administered for heart rates greater than $65 \mathrm{bpm}$. Using a dual-head power injector (Stellant, Medrad, Indianola, PA), cardiac CTA was performed with a tri-phasic consecutive injection sequence beginning with $50 \mathrm{ml}$ nonionic IV contrast material (Omnipaque, Amersham Health) injected at a rate of $5 \mathrm{ml} / \mathrm{s}$ followed by $50 \mathrm{ml}$ of a mixture of $60 \%$ contrast and normal saline and ending with a $50 \mathrm{ml}$ flush of normal saline. Contrast was injected through an 18- to 20 -gauge angiocatheter in an antecubital vein. All studies were performed by a 64 multi-detector computed tomography (MDCT) scanner (Lightspeed VCT, General Electric Healthcare Technologies, Milwaukee, WI). The following imaging and reconstruction parameters were applied: data acquisition collimation $0.625 \mathrm{~mm} \times 64=4 \mathrm{~cm} ; 140 \mathrm{kVp}$; 300-600 mAs; pitch 0.18-0.24; rotation time $0.35 \mathrm{~s}$; slice width $0.625 \mathrm{~mm}$; field of view $50 \mathrm{~cm}$; matrix $512 \times 512$. Cardiac data were reconstructed retrospectively at $0-90 \%$ of the $R-R$ interval at $0.625 \mathrm{~mm}$. Coronary vessels were reviewed on the workstation using commercial cardiac volume models (AW Volume Share ${ }^{\mathrm{TM}}$, GE Medical Systems, Milwaukee, WI). Two skilled cardiologists blinded to the clinical data assessed the coronary arteries separately. Discrepancies in interpretation between the reviewers were resolved by consensus (three cases). The coronary arteries were segmented according to American Heart Association guidelines, based on 16-segment classifications for evaluation of coronary artery stenosis. Each vessel segment was assessed as normal: no stenosis and CAC score $=0$, mild CAD: $1-30 \%$ stenosis, moderate CAD: $31-$ $69 \%$ stenosis, or severe CAD: $\geq 70 \%$ stenosis. Each segment was also classified as normal, non-obstructive CAD: luminal stenosis $<50 \%$, and obstructive CAD: luminal stenosis $\geq 50 \%$.

\section{Statistical analysis}

Mean \pm SD and proportions were used to summarize the characteristics of the study sample. Continuous variables were compared by ANOVA, and categorical variables were compared by the Kruskal-Wallis non-parametric ANOVA. Multivariate linear and logistic regression analyses were employed to assess 
the relationship of extent of CTA-diagnosed CAD and DTM indices, with and without adjustment for conventional cardiovascular risk factors, as well as for left ventricular ejection fraction. ROC curves were constructed and the area under the ROC curve (AUC) was calculated to predict the ability of each model to detect obstructive CAD. All statistical analyses were performed with SAS version 9.1 (SAS Institute Inc, Cary, NC, http://www.sas.com). The level of significance was set at $P<0.05$ (two-tailed). The study protocol and consent form were approved by IRB Committee Board of Los Angeles Biomedical Research Institute at Harbor UCLA Medical Center, Torrance, CA.

\section{Results}

Characteristics of the study population are highlighted in Table 1 according to the extent of CAD among the 129 consecutive participants (age $63 \pm 9$ years, $68 \%$ male). One hundred and one (78.3\%) had CTA-diagnosed CAD (27 with obstructive $\mathrm{CAD}$ and 74 with non-obstructive $\mathrm{CAD}$ ). There were no significant statistical differences between normal, non-obstructive and obstructive CAD cohorts in age, gender, hypertension, hypercholesterolemia, diabetes, smoking status, family history of premature CHD, left ventricular ejection fraction (LVEF), total cholesterol, HDL-C, LDL-C and triglyceride. FRS and CAC score increased significantly with increasing extent of CAD (Table 1).

Vascular function and coronary artery disease

Baseline fingertip temperature was not significantly different among the three groups $(P=0.39)$ (Table 1; Fig. 2a). Unadjusted DTM indices, TR and AUC, progressively decreased as the extent of CAD increased. Similarly, adjusted DTM indices, aTR and aTMP-AUC, significantly decreased from normal to non-obstructive CAD to obstructive CAD. Finally, the new DTM index of neurovascular reactivity, NVR, also decreased with a greater extent of CAD (Table 1; Fig. 2b-d).

Coronary artery calcium increased in each FRS category as vascular dysfunction increased; similarly, in each vascular function category as FRS increased. The maximum CAC was noted with the combination of the highest vascular dysfunction and CAC groups (Fig. 3a).

Extent of CAD increased with increasing CAC and vascular dysfunction. The most extensive $\mathrm{CAD}$ was observed in the group with maximum CAC and vascular dysfunction (Fig. 3b).

In linear regression analysis of single variables, FRS, DTM indices, and CAC were all independent predictors of obstructive CAD (Table 2a). As shown in Table $2 b$, various combination variables of DTM, FRS, and CAC resulted in higher predictive power for obstructive CAD. Maximum predictive power was observed ( $R$-square of 0.52$)$ with the combination of aTMP-AUC, NVR, CAC and FRS (Table 2b).

Multivariate logistic regression analysis showed that DTM indices and CAC were each independent predictors of the extent of CAD (Table 3). Of note, FRS was not an independent predictor $(P=0.08)$. After adjustment for age, gender and conventional cardiovascular risk factors, the odds ratio of lowest versus two upper tertiles of aTMP-AUC and NVR were 5.75 and 1.46 for non-obstructive $\mathrm{CAD}$ and 11.62 and 3.58 for obstructive CAD compared to normal cohorts, respectively (Table 3 ).

ROC curves were constructed to assess the independent as well as incremental diagnostic value of study variables to predict obstructive CAD. As shown in Fig. 4, FRS exhibited the lowest area under the ROC curve (ROC-AUC $=0.65 \pm 0.05,95 \%$ CI 0.54-0.76). The addition of DTM indices of vascular and neurovascular reactivity to FRS progressively increased the ROC-AUC (aTMP-AUC + FRS: ROC-AUC $=0.83 \pm 0.03, \quad 95 \% \quad$ CI $\quad 0.76-0.86$ ) $($ aTMP-AUC + NVR + FRS: ROC-AUC $=0.88 \pm$ 0.03 , 95\% CI $0.80-0.95), P=0.0001$ for all. Maximum predictive value was observed with the combination of FRS, aTMP-AUC, NVR, and CAC $(\mathrm{ROC}-\mathrm{AUC}=0.94 \pm 0.03,95 \%$ CI $0.85-0.98), P=$ 0.001 compared to FRS alone.

\section{Discussion}

The data clearly indicates a strong correlation between low fingertip temperature rebound measured by DTM and the presence and extent of CAD measured by CTA in this symptomatic population, independent of age, gender, and traditional risk factors. These results parallel our previous 
Table 1 Cardiovascular risk factors, DTM indices of vascular function, and the extent of CTA-diagnosed coronary artery disease

\begin{tabular}{|c|c|c|c|c|}
\hline & $\begin{array}{l}\text { Normal } \\
N=28\end{array}$ & $\begin{array}{l}\text { Non-obstructive CAD } \\
N=74\end{array}$ & $\begin{array}{l}\text { Obstructive CAD } \\
N=27\end{array}$ & $P$ value \\
\hline Age (years) & $61 \pm 9$ & $64 \pm 9$ & $65 \pm 10$ & 0.15 \\
\hline Male gender & $68 \%(19)$ & $65 \%(48)$ & $67 \%(18)$ & 0.8 \\
\hline Current smoker & $18 \%(5)$ & $16 \%(12)$ & $18 \%(5)$ & 0.8 \\
\hline SBP (mm Hg) & $134 \pm 21$ & $134 \pm 20$ & $135 \pm 21$ & 0.9 \\
\hline DBP (mm Hg) & $75 \pm 11$ & $75 \pm 12$ & $76 \pm 11$ & 0.6 \\
\hline Hypertension $^{\mathrm{a}}$ & $82 \%(23)$ & $84 \%(62)$ & $89 \%(24)$ & 0.23 \\
\hline Anti-hypertensive medication & $87 \%(20)$ & $87 \%(54)$ & $91 \%(22)$ & 0.57 \\
\hline Total cholesterol (mg/dl) & $170 \pm 28$ & $172 \pm 26$ & $180 \pm 26$ & 0.19 \\
\hline HDL-C (mg/dl) & $60 \pm 16$ & $58.4 \pm 15.3$ & $55.1 \pm 15.4$ & 0.66 \\
\hline LDL-C (mg/dl) & $93.1 \pm 28.5$ & $98.9 \pm 36.8$ & $91.6 \pm 31.4$ & 0.37 \\
\hline Triglycerides (mg/dl) & $91 \pm 43$ & $85 \pm 39$ & $118 \pm 37$ & 0.09 \\
\hline Hypercholesterolemia $^{\mathrm{b}}$ & $43 \%(12)$ & $45 \%(33)$ & $59 \%(16)$ & 0.06 \\
\hline Cholesterol-lowering medication & $83 \%(10)$ & $85 \%(28)$ & $81 \%(13)$ & 0.61 \\
\hline Diabetes mellitus $^{\mathrm{c}}$ & $18 \%(5)$ & $24 \%(18)$ & $30 \%(8)$ & 0.13 \\
\hline Family history of $\mathrm{CHD}^{\mathrm{d}}$ & $32 \%(9)$ & $34 \%(25)$ & $37 \%(10)$ & 0.8 \\
\hline Body mass index $\left(\mathrm{kg} / \mathrm{m}^{2}\right)$ & $29.7 \pm 4.1$ & $30.3 \pm 4.6$ & $30.4 \pm 3.9$ & 0.96 \\
\hline Framingham risk score $(\%)$ & $11.2 \pm 5.9$ & $13.7 \pm 6.8$ & $15.1 \pm 7.2$ & 0.01 \\
\hline LVEF & $63.9 \pm 4.9$ & $64.2 \pm 3.6$ & $63.5 \pm 4.6$ & 0.77 \\
\hline CAC score & 0 & $241 \pm 42$ & $720 \pm 124$ & 0.0001 \\
\hline Baseline fingertip temperature $\left({ }^{\circ} \mathrm{C}\right)$ & $29.2 \pm 1.8$ & $29.1 \pm 1.9$ & $28.1 \pm 2.3$ & 0.39 \\
\hline TR & $1.05 \pm 1.26$ & $0.52 \pm 0.85$ & $0.16 \pm 0.73$ & 0.01 \\
\hline aTR & $1.77 \pm 1.18$ & $1.24 \pm 1.14$ & $0.94 \pm 0.92$ & 0.009 \\
\hline TMP-AUC & $272.6 \pm 139.2$ & $225.5 \pm 152.6$ & $144.9 \pm 119.9$ & 0.009 \\
\hline aTMP-AUC & $355.6 \pm 242.4$ & $277.4 \pm 182.4$ & $184.4 \pm 171.2$ & 0.001 \\
\hline NVR & $161.5 \pm 147.4$ & $77.6 \pm 88.2$ & $48.8 \pm 63.8$ & 0.015 \\
\hline
\end{tabular}

Values presented as mean $\pm \mathrm{SD}$ or $\%$

NS $=$ Non-significant $(P>0.05)$

$\mathrm{LVEF}=$ Left ventricular ejection fraction on CTA

$\mathrm{CAC}=$ Coronary artery calcium score

$\mathrm{TR}=$ Temperature rebound in the fingertip of the occluded arm

aTR $=$ Adjusted TR

TMP-AUC $=$ Area under the fingertip temperature curve in the occluded arm

aTMP-AUC $=$ Adjusted TMP-AUC

$\mathrm{NVR}=$ Area under the fingertip temperature curve in non-occluded arm (neurovascular reactivity)

a Self-reported diagnosis of hypertension, prescribed medication for hypertension, or current blood pressure $>140 \mathrm{mmHg}$ systolic or $>90 \mathrm{mmHg}$ diastolic $(>130 / 80 \mathrm{mmHg}$ if diabetic)

b Self-reported diagnosis of high cholesterol, prescribed medication for high cholesterol, or current total cholesterol $>200 \mathrm{mg} / \mathrm{dl}$

c Self-reported diagnosis of diabetes (type 1 or 2 ) or prescribed medication for diabetes

${ }^{\mathrm{d}}$ First degree relative; female $<65$ years, male $<55$ years

observations in asymptomatic populations that showed low fingertip temperature rebound measured by DTM was associated with both risk factors as measured by FRS and subclinical coronary atherosclerosis as measured by CAC [10-12]. Our study also corroborates an earlier study by Tarjen et al. 

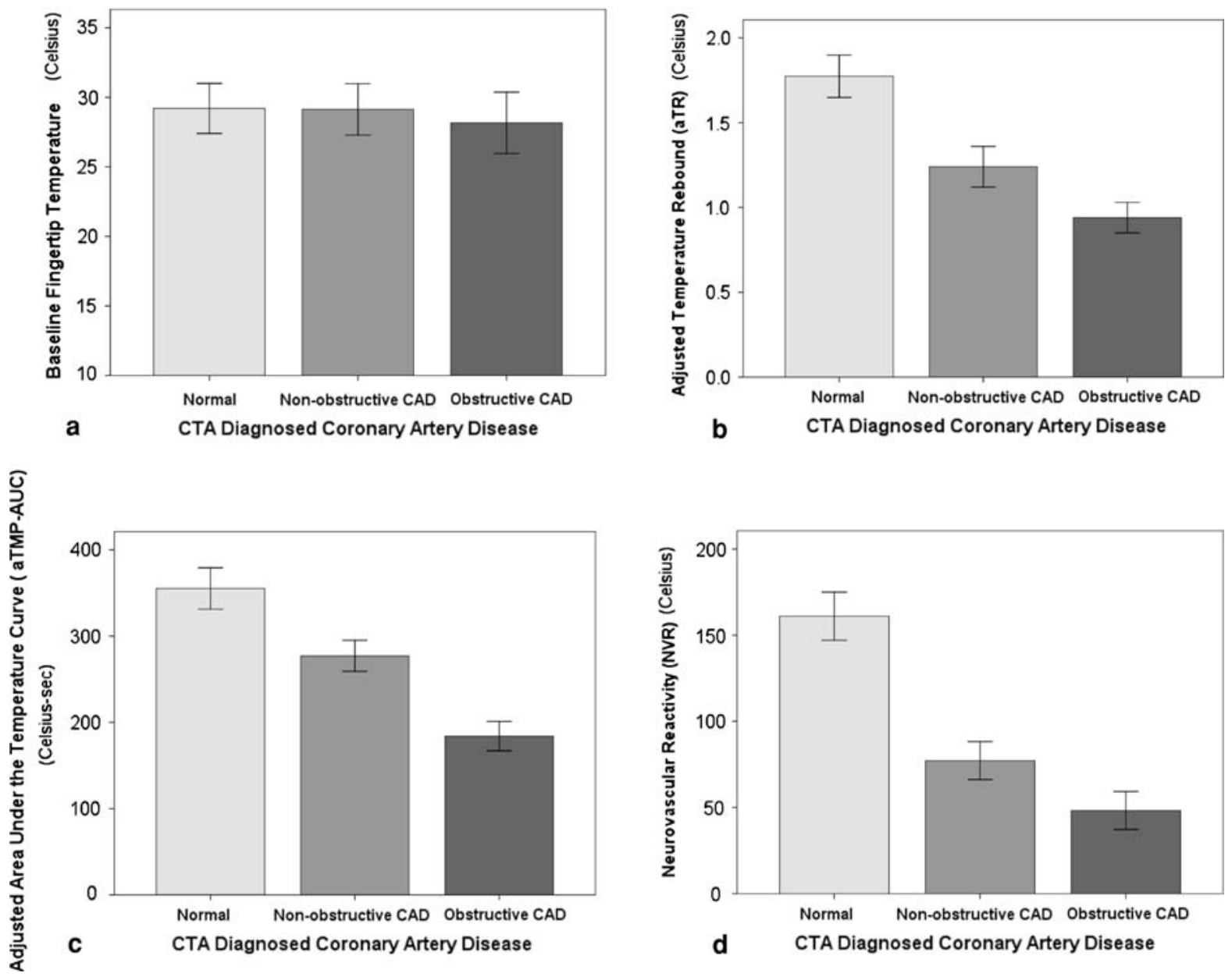

Fig. 2 Baseline fingertip temperature was not significantly different among the three CAD groups (a). aTR (b) and aTMPAUC (c), DTM indices of vascular function proportionally

which reported that in patients with chest pain, low fingertip temperature rebound was strongly associated with myocardial infarction [9]. Parallel to this CTA study, our group has also evaluated DTM in symptomatic patients undergoing myocardial perfusion imaging (MPI) using single photon emission computed tomography (SPECT) and found a strong inverse correlation between fingertip temperature rebound (TR) and abnormal myocardial perfusion, as measured by summed stress score (SSS) [11].

Vascular reactivity: a vital component of the circulatory system

Vascular reactivity is a vital component of vascular function that enables the circulatory system to

with the extent of CAD. NVR (d), DTM index of neurovascular reactivity, decreased from mild to moderate to severe CAD among CTA diagnosed CAD patients

respond to physiologic and pharmacologic stimuli that require adjustments of blood flow and alterations of vessel tone and diameter [21]. Vascular reactivity can be exhibited at both the macro-vascular and micro-vascular levels. "Macro-vascular" pertains to large, conduit arteries, and "micro-vascular" refers to small, resistance vessels. Micro-vascular reactivity causes reactive hyperemia, whereas macro-vascular reactivity (flow-mediated dilatation or FMD) results from reactive hyperemia. Both macro- and microvascular reactivity are governed by multiple physiologic (endothelium-dependent and -independent) regulatory mechanisms and are mediated by a number of biochemical agents, such as nitric oxide (NO), endothelium-derived hyperpolarizing factor (EDHF), prostaglandins, adenosine, bradykinin, histamine, and 

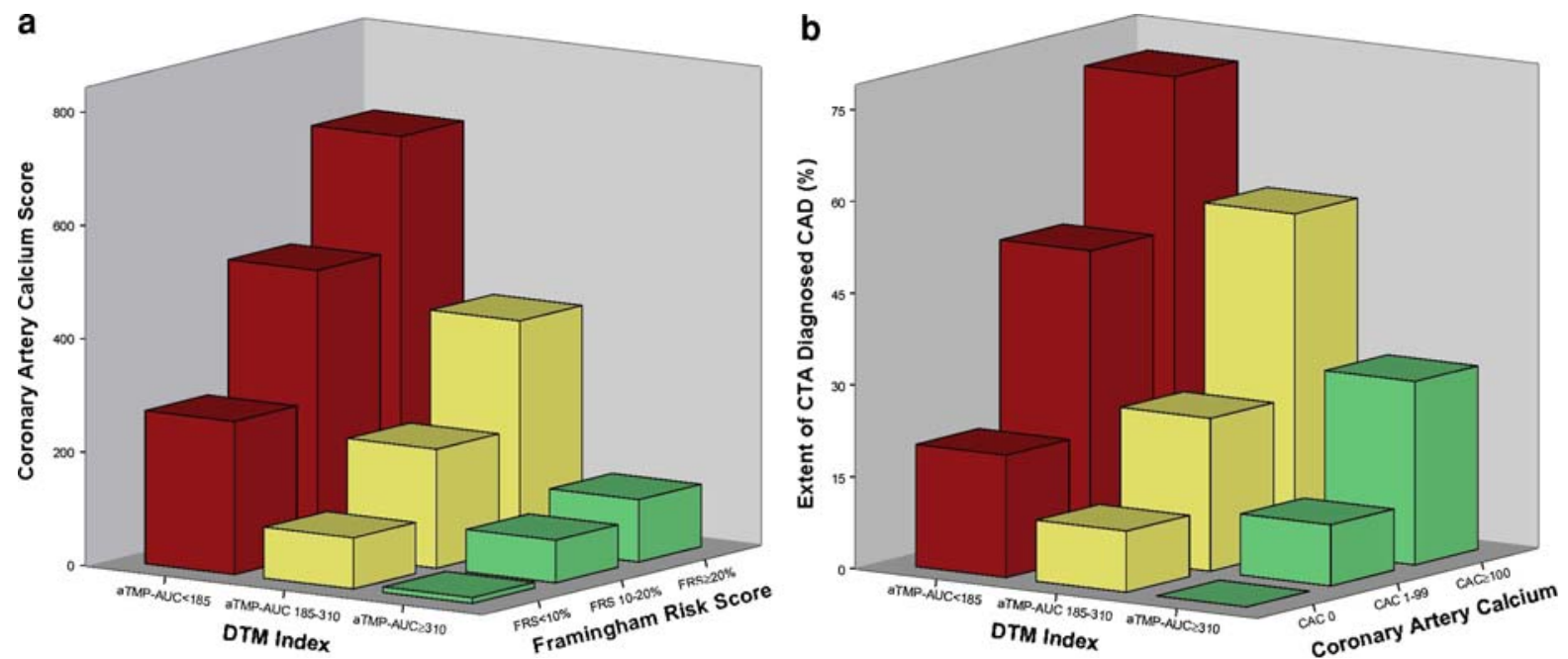

Fig. 3 a Coronary artery calcium increased by increasing Framingham risk score and vascular dysfunction, b extent of CTA diagnosed CAD increased with increasing coronary artery calcium and vascular dysfunction

other vasoactive substances [21-23]. It is believed that macro-vascular reactivity is predominantly mediated by endothelium-derived NO, whereas microvascular reactivity is only partially mediated by NO [21, 24]. Traditionally, assessment of macro-vascular reactivity (FMD) at the brachial artery level by high resolution ultrasound imaging has been described as an endothelial function test $[25,26]$. However, some believe that "endothelial function" is a misnomer because endothelial cells have numerous functions. Indeed, endothelial cells exist in all vascular beds, explaining the common root of vascular disease in various organs (such as heart, brain, kidney, eyes, legs, and urogenital) and the close correlation reported between peripheral and coronary vascular reactivity [27-29].

Impaired vascular reactivity and atherosclerotic cardiovascular disease

Previous studies have demonstrated the relationship between impaired micro- and macro-vascular reactivity and atherosclerotic cardiovascular disease [29-38]. Similarly, several studies have demonstrated strong correlations between endothelialdependent and independent vascular dysfunction and cardiovascular risk factors [33]. Nevertheless, there is a considerable heterogeneity in the magnitude of vascular dysfunction in individuals with similar risk factor profiles [29, 39] In this regard, vascular dysfunction may be seen as an important "integrative factor" of the inherent atherosclerotic risk of an individual, taking into account the cumulative effect of various risk and protective factors [36]. In addition to risk assessment for prediction of outcomes, another important aspect of using vascular function is to evaluate response to therapies [40-45].

In our recent studies of patients receiving treatments, improved vascular function measured by DTM correlated strongly with the slowed progression of CAC $\left(r^{2}=0.90, P<0.001\right)$ and increased clearance of oxidized phospholipids (Ox-phospholipid/ apoB) $\left(r^{2}=0.81, P<0.001\right)[46]$.

Skin vascular and neurovascular reactivity

Skin vascular response is believed to be primarily due to micro-vascular reactivity; however, it is also mediated by neurovascular interactions. Numerous studies have shed light on the pathophysiology of skin vascular reactivity and its significance in patients with vascular disease [23, 47-51]. Nabel et al. [52] and Prior et al. [53] have shown that the response of myocardial blood flow and epicardial coronary arteries to sympathetic stimulation with cold pressor test is significantly different in patients with and without CAD. Jzerman et al. [54] have found that individuals at high risk of CAD exhibit impaired micro-vascular function in skin. Moreover, recent studies have 
Table 2 Linear regression analysis of the relationship between the extent of coronary artery disease diagnosed by CTA and cardiovascular risk factors $(\beta, 95 \% \mathrm{CI})$

\begin{tabular}{|c|c|c|c|c|c|c|}
\hline Models & & $R$ & $R^{2}$ & $\beta$ & $95 \% \mathrm{CI}$ & $P$ value \\
\hline \multicolumn{7}{|c|}{ a: Single variables } \\
\hline II & CAC & 0.48 & 0.24 & 0.49 & 0.01 to 0.55 & 0.0001 \\
\hline III & $\mathrm{TR}$ & 0.29 & 0.11 & -0.34 & -0.05 to -0.42 & 0.001 \\
\hline IV & aTR & 0.32 & 0.12 & -0.39 & -0.02 to -0.51 & 0.001 \\
\hline IV & TMP-AUC & 0.38 & 0.14 & -0.38 & -0.02 to -0.46 & 0.0001 \\
\hline $\mathrm{V}$ & aTMP-AUC & 0.43 & 0.18 & -0.43 & -0.01 to -0.66 & 0.0001 \\
\hline VI & NVR & 0.28 & 0.08 & -0.28 & -0.001 to -0.46 & 0.009 \\
\hline \multicolumn{7}{|c|}{$b$ : Combination variables } \\
\hline \multirow[t]{3}{*}{ VII } & NVR & 0.40 & 0.17 & -0.17 & -0.001 to -0.45 & 0.01 \\
\hline & + & & & & & \\
\hline & aTR & & & -0.41 & -0.003 to -0.62 & 0.009 \\
\hline \multirow[t]{3}{*}{ VIII } & NVR & 0.53 & 0.28 & -0.19 & -0.001 to -0.43 & 0.006 \\
\hline & + & & & & & \\
\hline & TMP-AUC & & & -0.45 & -0.02 to -0.64 & 0.0001 \\
\hline \multirow[t]{5}{*}{ IX } & NVR & 0.71 & 0.51 & -0.11 & -0.001 to -0.19 & 0.03 \\
\hline & + & & & & & \\
\hline & aTMP-AUC & & & -0.46 & -0.02 to -0.59 & 0.0001 \\
\hline & + & & & & & 0.0002 \\
\hline & CAC & & & 0.36 & 0.02 to 0.48 & \\
\hline \multirow[t]{7}{*}{$\mathrm{X}$} & NVR & 0.72 & 0.52 & -0.14 & 0.001 to 0.41 & 0.03 \\
\hline & + & & & & & \\
\hline & aTMP-AUC & & & -0.47 & -0.02 to -0.51 & 0.0001 \\
\hline & + & & & & & \\
\hline & CAC & & & 0.35 & -0.003 to -0.22 & 0.003 \\
\hline & + & & & & & \\
\hline & FRS & & & 0.12 & -0.001 to 0.21 & 0.2 \\
\hline
\end{tabular}

Dependent variable: CTA diagnosed CAD

FRS $=$ Framingham risk score

$\mathrm{CAC}=$ Coronary artery calcium score

$\mathrm{TR}=$ Temperature rebound in the fingertip of the occluded arm

aTR $=$ Adjusted TR

TMP-AUC = Area under the fingertip temperature curve in the occluded arm

aTMP-AUC $=$ Adjusted TMP-AUC

$\mathrm{NVR}=$ Area under the fingertip temperature curve in non-occluded arm (neurovascular reactivity)

shown that skin vascular reactivity was significantly improved after statin therapy [44, 45, 55].

In our DTM studies, we unexpectedly found increased fingertip temperature during and after cuff occlusion in the contra-lateral (non-occluded) arm. We further confirmed our DTM findings using infrared thermal imaging of both hands (see Fig. 1a) and verified that increasing fingertip temperature in the contra-lateral hand during and after cuff occlusion was indeed due to a cutaneous vasodilative response, not from artifactual drifts in temperature probes. Although observations need additional investigations to elucidate the underlying molecular and cellular mechanism involved in this phenomenon, we believe that it is a neurovascular response and may involve endothelial- or neuronal-nitric oxide synthase (eNOS 
Table 3 Multivariate logistic regression analysis of the relationship between obstructive coronary artery disease, increased vascular dysfunction, coronary artery calcification and Framingham risk score (odds ratio, 95\% CI)

\begin{tabular}{|c|c|c|c|}
\hline Model & Normal & Non-obstructive CAD & Obstructive CAD \\
\hline \multicolumn{4}{|l|}{ Unadjusted } \\
\hline Odds of TR & 1 (ref) & $4.10(1.8-12.7), P=0.005$ & $8.90(1.9-14.6), P=0.002$ \\
\hline Odds of aTR & 1 (ref) & $4.23(1.8-9.5), P=0.001$ & $10.78(2.9-24.7), P=0.001$ \\
\hline Odds of TMP-AUC & 1 (ref) & $5.35(2.1-9.4), P=0.0001$ & $10.31(3.5-17.65), P=0.0001$ \\
\hline Odds of aTMP-AUC & 1 (ref) & $6.19(2.4-15.9), P=0.0001$ & $12.14(5.5-25.4), P=0.0001$ \\
\hline Odds of NVR & 1 (ref) & $1.59(1.05-3.2), P=0.04$ & $4.69(1.63-13.5), P=0.004$ \\
\hline Odds of CAC & 1 (ref) & $6.04(1.3-18.6), P=0.0001$ & $11.87(2.4-20.2), P=0.0001$ \\
\hline Odds of FRS & 1 (ref) & $1.09(0.7-1.7), P=0.74$ & $1.72(1.0-3.1), P=0.08$ \\
\hline \multicolumn{4}{|c|}{ Adjusted for age, gender, diabetes mellitus, hypertension, hypercholesterolemia, family history of CHD, smoking status } \\
\hline Odds of TR & 1 (ref) & $3.82(1.1-14.2), P=0.007$ & $8.51(1.8-19.6), P=0.005$ \\
\hline Odds of aTR & 1 (ref) & $3.90(1.7-7.6), P=0.001$ & $8.69(2.6-9.2), P=0.001$ \\
\hline Odds of TMP-AUC & 1 (ref) & $4.37(1.7-16.1), P=0.003$ & $9.61(3.1-18.1), P=0.002$ \\
\hline Odds of aTMP-AUC & 1 (ref) & $5.76(2.1-19.6), P=0.002$ & $11.63(5.1-28.5), P=0.001$ \\
\hline Odds of NVR & 1 (ref) & $1.49(1.01-3.4), P=0.05$ & $3.61(1.1-11.6), P=0.009$ \\
\hline Odds of CAC & 1 (ref) & $5.62(1.4-12.8), P=0.006$ & $10.53(2.3-25.1), P=0.002$ \\
\hline Odds of FRS & 1 (ref) & $1.04(0.6-1.5), P=0.85$ & $1.69(0.9-2.9), P=0.21$ \\
\hline
\end{tabular}

Odds of lowest tertile versus two upper tertiles for TR, aTR, TMP-AUC, aTMP-AUC, and NVR; Odds of FRS $\geq 20$ versus FRS $<20$; Odds of CAC $\geq 100$ versus CAC $<100$

FRS $=$ Framingham risk score

$\mathrm{CAC}=$ Coronary artery calcium score

$\mathrm{TR}=$ Temperature rebound in the fingertip of the occluded arm

aTR $=$ Adjusted TR

TMP-AUC $=$ Area under the fingertip temperature curve in the occluded arm

aTMP-AUC $=$ Adjusted TMP-AUC

$\mathrm{NVR}=$ Area under the fingertip temperature curve in non-occluded arm (neurovascular reactivity)

and nNOS) activity [56]. Surprisingly, in our multivariate analysis, we found that changes in fingertip temperature of the non-occluded arm (NVR) was significantly and independently correlated with both non-obstructive CAD (odd ratio 1.49 (95\% CI 1.01$3.4), P=0.05$ ) and obstructive CAD (odds ratio 3.61 (95\% CI 1.1-11.6), $P=0.009$ ) (Table 3). The higher the NVR, the likelihood of CAD will be lower.

Vascular dysfunction and CAD in symptomatic patients

Previous studies showed that impaired vascular reactivity measured at the macro-vascular level (brachial artery flow mediated dilation) correlates with adverse outcomes in patients with chest pain but without prior CAD $[57,58]$. Our study provides new evidence in addition to those reported by Tarjen et al.
[9] that impaired vascular reactivity measured by DTM at the skin level (predominantly micro-vascular) correlates strongly with the presence and extent of CTA-diagnosed CAD in symptomatic patients without prior history of cardiovascular disease.

Clinical implications

The appreciation for new screening tests and better cardiovascular risk assessment of asymptomatic population who have normal cholesterol has just increased in light of the JUPITER trial [59]. In this trial of apparently healthy individuals without hypercholesterolemia but with elevated high-sensitivity C-reactive protein (Hs-CRP) levels, rosuvastatin significantly reduced the incidence of major cardiovascular events. Furthermore, the incidence of major cardiovascular events increased significantly 

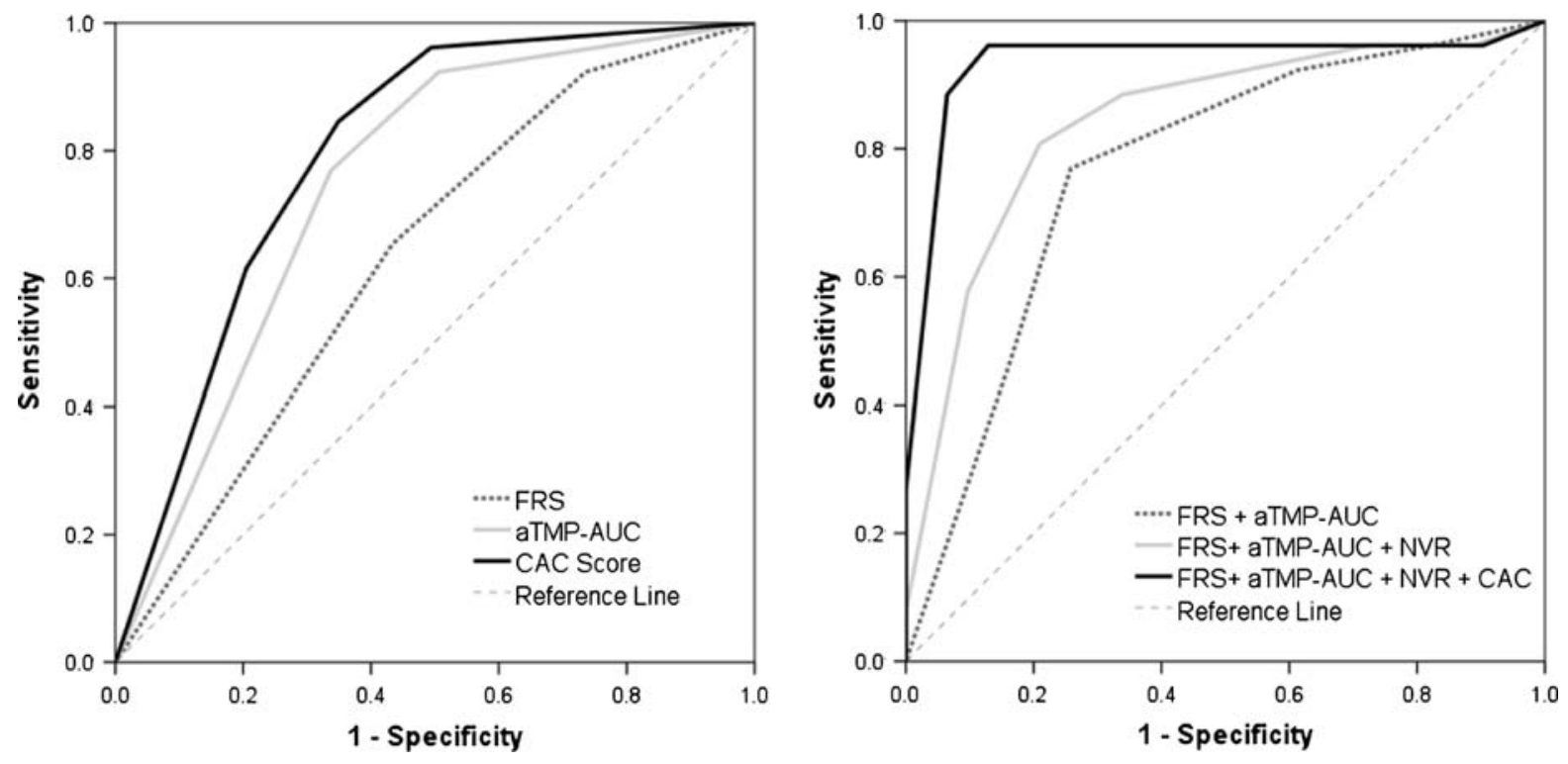

Fig. 4 ROC curves to assess the diagnostic accuracy of DTM of vascular reactivity and clinical variables for the detection of obstructive coronary artery disease

in apparently healthy subjects with elevated Hs-CRP in the control group [52]. Although high-sensitive $\mathrm{C}$ reactive protein (hs-CRP) and other markers of systemic inflammation may partly reflect the effect of risk factors on vascular wall, they do not measure the status of the vascular function. Therefore, direct assessment of the vascular system is needed. Such a test must be noninvasive, easy to use and widely available in order to make a difference in the primary prevention of atherosclerotic cardiovascular disease. The strong association between vascular and neurovascular dysfunction measured by DTM shown in this study reconfirms previous findings by our group and others [9-11, 60] and suggests a potential role for this simple noninvasive test in evaluation of at risk individuals in addition to risk factor measurements.

Limitation

The present study has several limitations. Tobacco, alcohol, caffeine, vasoactive medications, exercise, high-fat foods, vitamin $\mathrm{C}$, and uncontrolled ambient temperature can affect vascular function assessment; however, these were taken into consideration in this study. Beta blockers which are vasoactive medications, were administered for heart rates greater than
$65 \mathrm{bpm}$. However, recent studies demonstrated that concomitant therapy with non-nitrate vasoactive drugs has no significant effect on vascular function assessment [61]. Because of the cross-sectional design, we cannot establish causal relationships between CAD and DTM of vascular reactivity; however, our findings support the possibility of a link between the extent of CAD and the degree of vascular dysfunction measured by DTM. It is widely known that even severe vascular dysfunction may be present even in the absence of flow-limiting epicardial coronary lesions. However, our study demonstrated that patients with combined severe vascular dysfunction and increased FRS had a higher likelihood of non-obstructive and obstructive CAD.

\section{Conclusion}

Vascular and neurovascular dysfunction measured by DTM is associated with the presence and extent of coronary artery disease measured by CTA, independent of age, gender and traditional cardiovascular risk factors. The addition of vascular dysfunction measured by DTM to the FRS provided incremental value for the detection of obstructive and non-obstructive $\mathrm{CAD}$ on CTA. Prospective studies are needed to 
determine the clinical utility and cost effectiveness of incorporating DTM in coronary risk assessment.

Open Access This article is distributed under the terms of the Creative Commons Attribution Noncommercial License which permits any noncommercial use, distribution, and reproduction in any medium, provided the original author(s) and source are credited.

\section{References}

1. Naghavi M (2007) Preventive cardiology: the SHAPE of the future. A synopsis from the screening for heart attack prevention and education (SHAPE) task force report. Herz 32(5):356-361

2. Naghavi M, Falk E, Hecht HS, Jamieson MJ, Kaul S, Berman D, Fayad Z, Budoff MJ, Rumberger J, Naqvi TZ, Shaw LJ, Faergeman O, Cohn J, Bahr R, Koenig W, Demirovic J, Arking D, Herrera VL, Badimon J, Goldstein JA, Rudy Y, Airaksinen J, Schwartz RS, Riley WA, Mendes RA, Douglas P, Shah PK (2006) From vulnerable plaque to vulnerable patient-Part III: executive summary of the screening for heart attack prevention and education (SHAPE) task force report. Am J Cardiol 98(2A):2H-15H

3. Naghavi M, Falk E, Hecht HS, Shah PK (2006) The first SHAPE (screening for heart attack prevention and education) guideline. Crit Pathw Cardiol 5(4):187-190

4. Lau KK, Chan YH, Yiu KH, Tam S, Li SW, Lau CP, Tse HF (2008) Incremental predictive value of vascular assessments combined with the Framingham risk score for prediction of coronary events in subjects of low-intermediate risk. Postgrad Med J 84(989):153-157

5. Campuzano R, Moya JL, Garcia-Lledo A, Tomas JP, Ruiz S, Megias A, Balaguer J, Asin E (2006) Endothelial dysfunction, intima-media thickness and coronary reserve in relation to risk factors and Framingham score in patients without clinical atherosclerosis. J Hypertens 24(8):15811588

6. Juonala M, Viikari JS, Laitinen T, Marniemi J, Helenius H, Ronnemaa T, Raitakari OT (2004) Interrelations between brachial endothelial function and carotid intima-media thickness in young adults: the cardiovascular risk in young Finns study. Circulation 110(18):2918-2923

7. Schmieder RE, Schobel HP (1995) Is endothelial dysfunction reversible? Am J Cardiol 76(2):117A-121A

8. Westphal S, Abletshauser C, Luley C (2008) Fluvastatin treatment and withdrawal: effects on endothelial function. Angiology 59(5):613-618

9. Tarján J, Nagy L, Kovács I, Kovács E, Árvai F, Dobai F (2005) Flow mediated change of finger-tip-temperature in patients with high cardiovascular risk. Cardiol Hung 35:11-16

10. Gul KM, Ahmadi N, Wang Z, Jamieson C, Nasir K, Metcalfe R, Hecht HS, Hartley CJ, Naghavi M (2009) Digital thermal monitoring of vascular function: a novel tool to improve cardiovascular risk assessment. Vasc Med 14(2):143-148
11. Ahmadi N, Usman N, Shim J, Nuguri V, Vasinrapee P, Hajsadeghi F, Wang Z, Foster GP, Nasir K, Hecht H, Naghavi M, Budoff M (2009) Vascular dysfunction measured by fingertip thermal monitoring is associated with the extent of myocardial perfusion defect. J Nucl Cardiol 16(3):431-439

12. Ahmadi N, Hajsadeghi F, Gul K, Vane J, Usman N, Flores F, Nasir K, Hecht H, Naghavi M, Budoff M (2008) Relations between digital thermal monitoring of vascular function, the Framingham risk score, and coronary artery calcium score. J Cardiovasc Comput Tomogr 2(6):382-388

13. Wilson PW, D'Agostino RB, Levy D, Belanger AM, Silbershatz H, Kannel WB (1998) Prediction of coronary heart disease using risk factor categories. Circulation 97(18): 1837-1847

14. Hayashi N, Someya N, Hirooka Y, Koga S (2008) Ambient temperature affects glabrous skin vasculature and sweating responses to mental task in humans. J Physiol Anthropol 27(5):227-231

15. Thoden J, Kenny G, Reardon F, Jette M, Livingstone S (1994) Disturbance of thermal homeostasis during postexercise hyperthermia. Eur J Appl Physiol Occup Physiol 68(2): $170-176$

16. Curri SB (1990) Microvascular anatomy of the skin and its appendages. Phlebologie 43(3):407-430

17. Holowatz LA, Thompson-Torgerson CS, Kenney WL (2008) The human cutaneous circulation as a model of generalized microvascular function. J Appl Physiol 105(1):370-372

18. Charkoudian N (2003) Skin blood flow in adult human thermoregulation: how it works, when it does not, and why. Mayo Clin Proc 78(5):603-612

19. Kellogg DL Jr (2006) In vivo mechanisms of cutaneous vasodilation and vasoconstriction in humans during thermoregulatory challenges. J Appl Physiol 100(5):17091718

20. Becker CR, Knez A, Jakobs TF, Aydemir S, Becker A, Schoepf UJ, Bruening R, Haberl R, Reiser MF (1999) Detection and quantification of coronary artery calcification with electron-beam and conventional CT. Eur Radiol 9(4):620-624

21. Dhindsa M, Sommerlad SM, DeVan AE, Barnes JN, Sugawara J, Ley O, Tanaka H (2008) Interrelationships among noninvasive measures of postischemic macro- and microvascular reactivity. J Appl Physiol 105(2):427-432

22. Coats P, Johnston F, MacDonald J, McMurray JJ, Hillier C (2001) Endothelium-derived hyperpolarizing factor: identification and mechanisms of action in human subcutaneous resistance arteries. Circulation 103(12):1702-1708

23. Lenasi H, Strucl M (2008) The effect of nitric oxide synthase and cyclooxygenase inhibition on cutaneous microvascular reactivity. Eur J Appl Physiol 103(6):719-726

24. Vinik AI, Stansberry KB, Barlow PM (2003) Rosiglitazone treatment increases nitric oxide production in human peripheral skin: a controlled clinical trial in patients with type 2 diabetes mellitus. J Diabetes Complications 17(5):279-285

25. Celermajer DS, Sorensen KE, Gooch VM, Spiegelhalter DJ, Miller OI, Sullivan ID, Lloyd JK, Deanfield JE (1992) Non-invasive detection of endothelial dysfunction in 
children and adults at risk of atherosclerosis. Lancet 340(8828):1111-1115

26. Tonari S, Nishimura H, Fukunishi K, Mori T, Kitaura Y (2003) Forearm hyperemia is a better marker than carotid intima-media thickness or ankle-brachial index for coronary artery disease in Japanese males under 65. Hypertens Res 26(1):59-65

27. Anderson TJ, Uehata A, Gerhard MD, Meredith IT, Knab S, Delagrange D, Lieberman EH, Ganz P, Creager MA, Yeung AC et al (1995) Close relation of endothelial function in the human coronary and peripheral circulations. J Am Coll Cardiol 26(5):1235-1241

28. Bonetti PO, Pumper GM, Higano ST, Holmes DR Jr, Kuvin JT, Lerman A (2004) Noninvasive identification of patients with early coronary atherosclerosis by assessment of digital reactive hyperemia. J Am Coll Cardiol 44(11): 2137-2141

29. Huang AL, Silver AE, Shvenke E, Schopfer DW, Jahangir E, Titas MA, Shpilman A, Menzoian JO, Watkins MT, Raffetto JD, Gibbons G, Woodson J, Shaw PM, Dhadly M, Eberhardt RT, Keaney JF Jr, Gokce N, Vita JA (2007) Predictive value of reactive hyperemia for cardiovascular events in patients with peripheral arterial disease undergoing vascular surgery. Arterioscler Thromb Vasc Biol 27(10):2113-2119

30. Bugiardini R, Manfrini O, Pizzi C, Fontana F, Morgagni G (2004) Endothelial function predicts future development of coronary artery disease: a study of women with chest pain and normal coronary angiograms. Circulation 109(21): 2518-2523

31. Caballero AE, Arora S, Saouaf R, Lim SC, Smakowski P, Park JY, King GL, LoGerfo FW, Horton ES, Veves A (1999) Microvascular and macrovascular reactivity is reduced in subjects at risk for type 2 diabetes. Diabetes 48(9):1856-1862

32. Fichtlscherer S, Breuer S, Zeiher AM (2004) Prognostic value of systemic endothelial dysfunction in patients with acute coronary syndromes: further evidence for the existence of the "vulnerable" patient. Circulation 110(14): 1926-1932

33. Hayoz D, Weber R, Rutschmann B, Darioli R, Burnier M, Waeber B, Brunner HR (1995) Postischemic blood flow response in hypercholesterolemic patients. Hypertension 26(3):497-502

34. Heitzer T, Schlinzig T, Krohn K, Meinertz T, Munzel T (2001) Endothelial dysfunction, oxidative stress, and risk of cardiovascular events in patients with coronary artery disease. Circulation 104(22):2673-2678

35. Targonski PV, Bonetti PO, Pumper GM, Higano ST, Holmes DR Jr, Lerman A (2003) Coronary endothelial dysfunction is associated with an increased risk of cerebrovascular events. Circulation 107(22):2805-2809

36. Halcox JP, Schenke WH, Zalos G, Mincemoyer R, Prasad A, Waclawiw MA, Nour KR, Quyyumi AA (2002) Prognostic value of coronary vascular endothelial dysfunction. Circulation 106(6):653-658

37. Yeboah J, Crouse JR, Hsu FC, Burke GL, Herrington DM (2007) Brachial flow-mediated dilation predicts incident cardiovascular events in older adults: the cardiovascular health study. Circulation 115(18):2390-2397
38. Kirma C, Akcakoyun M, Esen AM, Barutcu I, Karakaya O, Saglam M, Kargin R, Turkmen M, Boztosun B, Izgi A, Sonmez K (2007) Relationship between endothelial function and coronary risk factors in patients with stable coronary artery disease. Circ J 71(5):698-702

39. Quyyumi AA (2003) Prognostic value of endothelial function. Am J Cardiol 91(12A):19H-24H

40. Warnholtz A, Wild P, Ostad MA, Elsner V, Stieber F, Schinzel R, Walter U, Peetz D, Lackner K, Blankenberg S, Munzel T (2009) Effects of oral niacin on endothelial dysfunction in patients with coronary artery disease: results of the randomized, double-blind, placebo-controlled INEF study. Atherosclerosis 204(1):216-221

41. Charbonneau F, Anderson TJ, Title L, Jobin J, Poirier P, Huyhn T, Chan S, Walling A, Hutchison S, Tran T, Lonn E, Buithieu J, Genest J (2008) Modulation of arterial reactivity using amlodipine and atorvastatin measured by ultrasound examination (MARGAUX). Atherosclerosis 197(1):420-427

42. Stulc T, Kasalova Z, Prazny M, Vrablik M, Skrha J, Ceska $\mathrm{R}$ (2003) Microvascular reactivity in patients with hypercholesterolemia: effect of lipid lowering treatment. Physiol Res 52(4):439-445

43. Minson CT, Wong BJ (2004) Reactive hyperemia as a test of endothelial or microvascular function? J Am Coll Cardiol 43(11):2147-2148

44. Celermajer DS (2003) Statins, skin, and the search for a test of endothelial function. J Am Coll Cardiol 42(1):78-80

45. Binggeli C, Spieker LE, Corti R, Sudano I, Stojanovic V, Hayoz D, Luscher TF, Noll G (2003) Statins enhance postischemic hyperemia in the skin circulation of hypercholesterolemic patients: a monitoring test of endothelial dysfunction for clinical practice? J Am Coll Cardiol 42(1):71-77

46. Ahmadi N, Bevinal MA, Hajsadeghi F, Sarraf G, Tirunagaram S, Foster GP, Tsimikas S, Hecht H, Naghavi M, Budoff M (2008) Relationship of oxidized LDL biomarkers persistent vascular dysfunction measured by fingertip digital thermal monitoring and progression of coronary artery calcification J Am Coll Cardiol. Submitted

47. Rossi M, Carpi A, Di Maria C, Franzoni F, Galetta F, Santoro G (2009) Skin blood flowmotion and microvascular reactivity investigation in hypercholesterolemic patients without clinically manifest arterial diseases. Physiol Res 58(1):39-47

48. Rossi M, Cupisti A, Di Maria C, Galetta F, Barsotti G, Santoro G (2008) Blunted post-ischemic increase of the endothelial skin blood flowmotion component as early sign of endothelial dysfunction in chronic kidney disease patients. Microvasc Res 75(3):315-322

49. NL TarjánJ, Kovács I, Kovács E, Árvai F, Dobai F (2005) Flow mediated change of finger-tip-temperature in patients with high cardiovascular risk. Cardiol Hung 35:11-16

50. Berghoff M, Kathpal M, Kilo S, Hilz MJ, Freeman R (2002) Vascular and neural mechanisms of ACh-mediated vasodilation in the forearm cutaneous microcirculation. $\mathrm{J}$ Appl Physiol 92(2):780-788

51. Minson CT, Berry LT, Joyner MJ (2001) Nitric oxide and neurally mediated regulation of skin blood flow during local heating. J Appl Physiol 91(4):1619-1626 
52. Nabel EG, Ganz P, Gordon JB, Alexander RW, Selwyn AP (1988) Dilation of normal and constriction of atherosclerotic coronary arteries caused by the cold pressor test. Circulation 77(1):43-52

53. Prior JO, Schindler TH, Facta AD, Hernandez-Pampaloni M, Campisi R, Dahlbom M, Schelbert HR (2007) Determinants of myocardial blood flow response to cold pressor testing and pharmacologic vasodilation in healthy humans. Eur J Nucl Med Mol Imaging 34(1):20-27

54. Jzerman RG I, De Jongh RT, Beijk MA, Van Weissenbruch MM, Delemarre-van de Waal HA, Serne EH CDS (2003) Individuals at increased coronary heart disease risk are characterized by an impaired microvascular function in skin. Eur J Clin Invest 33(7):536-542

55. Khan F, Litchfield SJ, Stonebridge PA, Belch JJ (1999) Lipid-lowering and skin vascular responses in patients with hypercholesterolaemia and peripheral arterial obstructive disease. Vasc Med 4(4):233-238

56. Kaufmann PA, Rimoldi O, Gnecchi-Ruscone T, Bonser RS, Luscher TF, Camici PG (2004) Systemic inhibition of nitric oxide synthase unmasks neural constraint of maximal myocardial blood flow in humans. Circulation 110(11): 1431-1436
57. Hasdai D, Gibbons RJ, Holmes DR Jr, Higano ST, Lerman A (1997) Coronary endothelial dysfunction in humans is associated with myocardial perfusion defects. Circulation 96(10):3390-3395

58. Zeiher AM, Krause T, Schachinger V, Minners J, Moser E (1995) Impaired endothelium-dependent vasodilation of coronary resistance vessels is associated with exerciseinduced myocardial ischemia. Circulation 91(9):2345-2352

59. Ridker PM, Danielson E, Fonseca FA, Genest J, Gotto AM Jr, Kastelein JJ, Koenig W, Libby P, Lorenzatti AJ, Macfadyen JG, Nordestgaard BG, Shepherd J, Willerson JT, Glynn RJ (2009) Rosuvastatin to prevent vascular events in men and women with elevated C-reactive protein. N Engl J Med 360(18):1851-1861

60. Roustit M, Simmons GH, Baguet JP, Carpentier P, Cracowski JL (2008) Discrepancy between simultaneous digital skin microvascular and brachial artery macrovascular post-occlusive hyperemia in systemic sclerosis. J Rheumatol 35(8):1576-1583

61. Gokce N, Holbrook M, Hunter LM, Palmisano J, Vigalok E, Keaney JF Jr, Vita JA (2002) Acute effects of vasoactive drug treatment on brachial artery reactivity. J Am Coll Cardiol 40(4):761-765 